\title{
Retrospective Evaluation of Injuries Around the Knee Region During Long Jump Attempt
}

\author{
Mustafa Çağlar Kır (1), Mehmet Taner Özdemir² (1) \\ 1'Department Orthopedics and Traumatology, University of Health Sciences Okmeydanı Training and Research Hospital, İstanbul, Turkey \\ 2Department Orthopedics and Traumatology, Anatolian Health Center, İstanbul, Turkey
}

Cite this article as: Kır MÇ, Özdemir MT. Retrospective Evaluation of Injuries Around the Knee Region During Long Jump Attempt. JAREM 2018; 8(3): 161-6.

\begin{abstract}
Objective: This study aimed to evaluate sports injuries around the knee joint during long jump attempt.

Methods: A total of 68 patients admitted to emergency service due to knee injury during long jump attempt were retrospectively investigated between January 2005 and January 2012. All cases were evaluated in terms of isolated or combined injuries of the knee and surrounding structures, long jump distance, injury side, demographic data and radiological findings. All injuries were classified into three groups according to the number of damaged anatomical structures. Study data were statistically evaluated using the Mann-Whitney U test, Pearson chi-square test, Fisher's exact test, and Fisher-Freeman-Halton exact test. Significance was evaluated at $p<0.01$ and $p<0.05$.

Results: All patients were male, and the age range was $23.25 \pm 2.82$ years. The incidence of the left-side injury was $63.2 \%$. Effusion was the common radiological finding. The incidence of anterior cruciate ligament injuries was the highest (66.2\%), followed by that of the medial meniscus (63.3\%), medial collateral ligament (25\%), lateral meniscus (22.1\%), lateral collateral ligament (11.8\%), extensor mechanism (10.3\%), and posterior cruciate ligament injuries (4.4\%). The incidence of anterior cruciate ligament and medial collateral ligament injuries of the right side was significantly higher than that of the left side $(p=0.016 ; p=0.014)$. No significant association was found between the long jump distance and injuries $(p=0.076)$.

Conclusion: All structures of the knee joint, particularly the anterior cruciate ligament, medial meniscus, and medial collateral ligament, appeared to be at high risk of injury during long jump attempt.
\end{abstract}

Keywords: Long jump, anterior cruciate ligament, meniscus, sports injury

ORCID IDs of the authors: M.Ç.K. 0000-0002-5073-7401; M.T.Ö. 0000-0002-9355-1455.

\section{INTRODUCTION}

The knee is the most frequently injured body part during sportive activities (1). It is estimated that $40 \%$ of sports injuries are related to the knee joint (2). The complex anatomical and biomechanical properties of the knee and the occasional overload may lead to frequent injuries (2). Injuries of the anterior cruciate ligament $(\mathrm{ACL})$ and other ligaments, meniscal lesions, bone marrow edema, and extensor mechanism injuries are common during sportive activities. These injuries can lead to early and late problems such as physical therapy and surgery, diminished athletic performance and time loss, chronic pain, and permanent loss of function in the knee joint $(3,4)$.

The long jump is a movement model for target-oriented displacement, a test with an extensive use to evaluate the lowerextremity explosive strength, and also a professional sport (5-7). It is also implemented in the Turkish Armed Forces as part of military sports exercises. Therefore, patients who have a knee injury during the long jump refer to the emergency departments of hospitals. Excessive valgus and extension of the knee during the deceleration on one foot can lead to these injuries.
The aim of this study is to retrospectively evaluate knee injuries that may occur during the long jump. The identification of injuries that may occur during the long jump may be useful for taking precautions in athletes and military personnel.

\section{METHODS}

Between January 2005 and January 2012, 83 cases who were admitted to the emergency department due to knee injury during the long jump were evaluated retrospectively. Our study was carried out in accordance with the ethical principles of the $1964 \mathrm{Hel}$ sinki Declaration. Fifteen patients who had a history of a previous knee injury or operation, who had rheumatologic and neurological problems, and whose records could not be reached were excluded from the study. During the admission, a detailed history of the cases, skip distance, athletic experience, and the injured side were recorded. Detailed physical and radiological findings of the affected extremity were evaluated. The two-way knee, tunnel, and tangential patella radiographs of all the cases were obtained as a standard procedure. Additional investigations such as magnetic resonance imaging (MRI), computed tomography, electromyography, and Doppler ultrasound (USG) were performed for 
further investigations in severe injuries.

The cases were divided into three groups to reveal the seriousness of the injury.

Group 1 (mild): The ligament, bone, tendon, or only one of the menisci is affected.

Group 2 (medium): Two anatomical structures were affected.

Group 3 (serious): More than two anatomical structures were affected.

Bone marrow edema, Grade 1-2 medial collateral ligament injuries, Grade 1-2 meniscal lesions, and partial extensor mechanism injuries were treated with load recovery, anti-inflammatory drugs, and physical therapy methods. Isolated ACL injuries were treated with physical therapy and conservative treatment for 2 months. In the recurred cases despite conservative treatment, reconstruction of the ACL was performed. A total extensor mechanism injury, femoral distal region fracture, Stage 3-4 meniscal lesion, and combined ligament injuries were treated surgically. The details

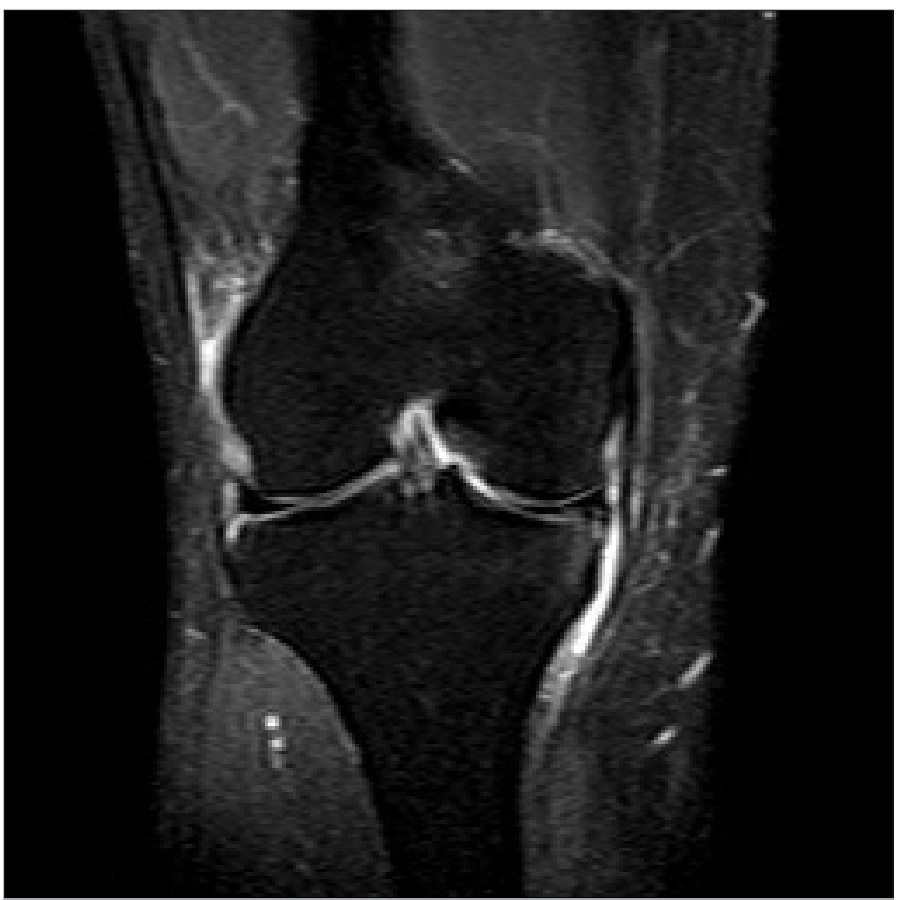

Figure 1. Coronal magnetic resonance imaging (MRI) cross section showing the internal lateral ligament and internal meniscal injury

Table 1. Distribution of descriptive characteristics such as age, gender, and the sprained side

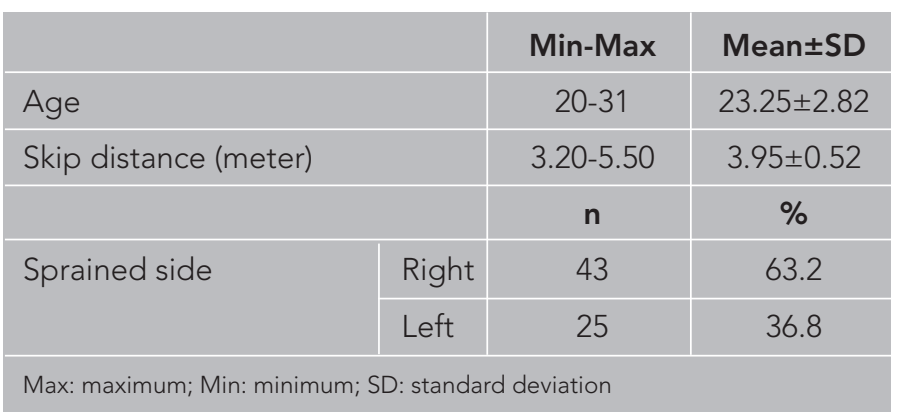

of the surgical treatment were not examined within the scope of this study.

This study was carried out in accordance with the ethical principles of the 1964 Helsinki Declaration.

\section{Statistical Analysis}

Data were analyzed using the Number Cruncher Statistical System 2007 \& Power Analysis and Sample Size 2008 statistical software (Utah, USA) program. In the evaluation of the data, descriptive statistical methods (mean, standard deviation, median, frequency, ratio, minimum, maximum) were used, as well as the Mann-Whitney $\mathrm{U}$ test, which was used for the comparison of quantitative data and two groups of the parameters that did not show normal distribution. Pearson's Chi-squared test, Fisher's exact test, and the Fisher-Freeman-Halton exact test were used to compare qualitative data. Spearman's correlation analysis was used to evaluate the relationships between the parameters. Significance was evaluated at the $p<0.01$ and $p<0.05$ levels.

\section{RESULTS}

Eighty-six male patients who had a knee injury during the long jump were evaluated retrospectively. The ages of the patients ranged between 20 and 31 with the mean age $23.25 \pm 2.82$ (Table 1). The right side was affected in $63.2 \%$ and the left side in $26.8 \%$ of the cases. All patients had an MRI and two-sided radiographs of the knee. Twelve cases had a knee USG. Effusion was the most common radiological finding (88.2\%). An isolated or combined ligament injury, meniscal tear, bone marrow edema, baker cyst, peroneal nerve paralysis, bone avulsion, extensor mechanism injury, tenosynovitis, and distal femur fracture were the other injuries. It has been found that $66.2 \%(n=45)$ of $A C L, 63.2 \%(n=43)$ of $I M, 25 \%(n=17)$ of $M C L, 22.1 \%(n=15)$ of $E M, 11.8 \%(n=8)$ of $L C L$, $6 \%(n=4)$ of $P C L$, and $10.3 \%(n=7)$ of the extensor mechanism were damaged (Table 2).

Combined injuries with more than one anatomical structure were present in $85 \%(n=58)$ of the patients. The ACL-lesion-associated bone marrow edema in $73.3 \%$, IM lesion in $64.4 \%(n=29), M C L$ injury in $28.9 \%(n=13)$, and EM lesion in $24.4 \%(n=11)$ of the cases were found (Table 3; Figures 1-3)

Isolated IM rupture (47.1\%) was the most frequently detected meniscal tear. It was followed by a combined IM and EM injury (16.2\%) and isolated EM lesion (5.9\%) respectively (Table 2). The ratio of EM injury to IM lesion was 1:3.

In our study, we evaluated whether there was a relationship between the injured knee structures and the sprained side. Accordingly, there was no significant difference between the sprained side and bone marrow edema, effusion, meniscal lesion, $L C L$, and PCL injuries (Table 4). However, the incidence of ACL lesions in the right-sided injuries was found to be statistically significantly higher than the left sided (effect size w, 0.293; post-hoc power, $0.676 ; p, 0.016 ; p<0.05)$. It was also found that the incidence of MLL lesions was significantly higher in the right-sided injuries than the left sided (effect size w, 0.299; post-hoc power, 0.694; $p$, $0.014 ; p<0.05)$. In this study, the skip distance was also evaluated. No relationship was found between the skip distance and the injury severity (Table 5). 
The MCL injury with ACL rupture was the most common combination of ligament lesions. Two patients had peroneal transient paralysis with avulsion fracture. Other serious problems were the extensor mechanism (10.3\%) injury and a distal femur fracture in 1 patient.

Of the patients, $60.3 \%$ were treated surgically and $39.7 \%$ conservatively (Figures 4 and 5). One patient with a total extensor mechanism injury, 1 patient with a combined extensor mechanism injury and ACL injury, and 2 patients with a distal femur fracture were treated surgically in the first 48 hours.

\section{Table 2. Distributions related to injuries around the knee}

\begin{tabular}{|c|c|c|c|}
\hline \multicolumn{2}{|c|}{ 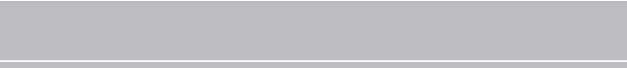 } & $\mathrm{n}$ & $\%$ \\
\hline \multicolumn{2}{|c|}{ Bone marrow edema } & 46 & 67.6 \\
\hline \multicolumn{2}{|c|}{ Effusion } & 60 & 88.2 \\
\hline \multirow[t]{4}{*}{ Meniscal tear } & No & 21 & 30.9 \\
\hline & EM & 4 & 5.9 \\
\hline & IM & 32 & 47.1 \\
\hline & $\mathrm{IM}+\mathrm{EM}$ & 11 & 16.2 \\
\hline \multirow{2}{*}{ Meniscal injury } & EM & 15 & 22.1 \\
\hline & IM & 43 & 63.2 \\
\hline \multirow[t]{10}{*}{ Ligament injury } & No & 14 & 20.6 \\
\hline & $\mathrm{ACL}$ & 30 & 44.1 \\
\hline & $\mathrm{LCL}$ & 3 & 4.4 \\
\hline & $\mathrm{MCL}$ & 3 & 4.4 \\
\hline & $\mathrm{ACL}+\mathrm{PCL}$ & 1 & 1.5 \\
\hline & $\mathrm{ACL}+\mathrm{LCL}$ & 2 & 2.9 \\
\hline & $\mathrm{ACL}+\mathrm{MCL}$ & 12 & 17.6 \\
\hline & $\mathrm{PCL}+\mathrm{LCL}$ & 2 & 2.9 \\
\hline & $\mathrm{PCL}+\mathrm{MCL}$ & 1 & 1.5 \\
\hline & $\mathrm{LCL}+\mathrm{MCL}$ & 1 & 1.5 \\
\hline \multirow[t]{9}{*}{ Ligament injury } & $\mathrm{ACL}$ & 45 & 66.2 \\
\hline & LCL & 8 & 11.8 \\
\hline & $\mathrm{MCL}$ & 17 & 25.0 \\
\hline & PCL & 4 & 6.0 \\
\hline & Baker's cyst & 5 & 7.4 \\
\hline & $\begin{array}{l}\text { Avulsion fracture, } \\
\text { peroneal paralyses }\end{array}$ & 2 & 2.9 \\
\hline & Distal femur fracture & 1 & 1.5 \\
\hline & $\begin{array}{l}\text { Extensor mechanism } \\
\text { injury }\end{array}$ & 7 & 10.3 \\
\hline & $\begin{array}{l}\text { Pes anserinus } \\
\text { tenosynovitis }\end{array}$ & 1 & 1.5 \\
\hline
\end{tabular}

\section{DISCUSSION}

The knee is the most commonly affected joint due to its complex anatomical and biomechanical properties (8). The muscle, tendon, ligament, and joint capsule together contribute to the static and dynamic stability of the knee joint (9). An abnormal load and movement pattern that may occur during sportive activities may impair this stability and cause an excessive use injury around the joint (9). Kuikka et al. (10) in the study on acute sports injuries in the Finnish army determined the most frequent ones to be the extensor mechanism injury (22\%), meniscal tear (20\%), ACL-PCL (19\%), MCL-LCL (9\%), and cartilage lesion (2\%). Majewski et al. (2) reported that $39.8 \%$ of all sports injuries were related to the knee joint in their large-scale retrospective study, and the ACL injury $(20 \%)$ was the most common one. Subsequently, they found

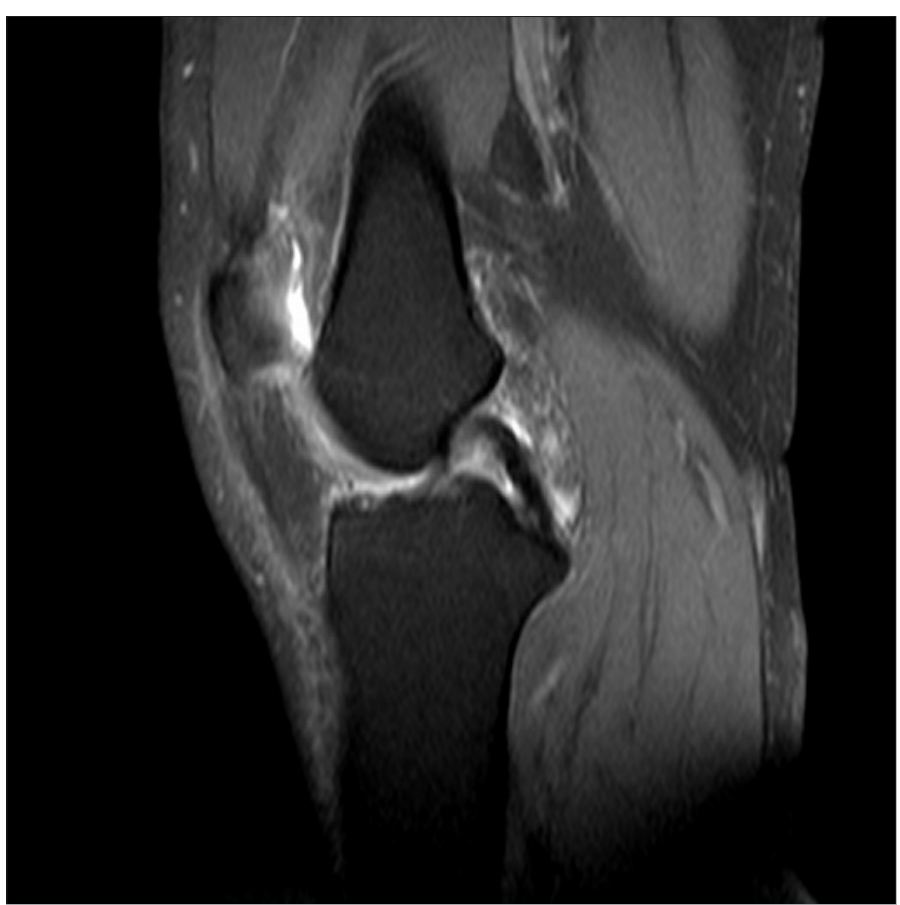

Figure 2. Sagittal MRI section showing the anterior cruciate ligament $(\mathrm{ACL})$ injury

Table 3. Other injuries associated with an anterior cruciate ligament lesion

\begin{tabular}{|c|c|c|c|}
\hline & \multicolumn{2}{|c|}{ ACL Injury } & \\
\hline & - & + & \\
\hline & n (\%) & n (\%) & ${ }^{a} p$ \\
\hline EM & $4(17.4)$ & $11(24.4)$ & 0.507 \\
\hline IM & $14(60.9)$ & $29(64.4)$ & 0.772 \\
\hline $\mathrm{MCL}$ & $4(17.4)$ & $13(28.9)$ & 0.300 \\
\hline $\mathrm{LCL}$ & $5(21.7)$ & $3(6.7)$ & b0.109 \\
\hline PCL & $3(13.0)$ & $0(0.0)$ & b0.035 \\
\hline Extensor Mechanism & $4(17.4)$ & $3(6.7)$ & ${ }^{b} 0.215$ \\
\hline
\end{tabular}


that the medial meniscus, lateral meniscus, medial collateral ligament, lateral collateral ligament, and posterior cruciate ligament were injured, respectively (2). In the present study, it was seen that during the long jump, the $A C L$ was injured in $66.2 \%, I M$ in $63.3 \%, \mathrm{MCL}$ in $25 \%$, EM in $22.1 \%, \mathrm{LCL}$ in $11.7 \%, \mathrm{PCL}$ in $4.4 \%$, and the extensor mechanism in $10.3 \%$ of the cases. It is noteworthy that these rates are higher in the literature $(2,10)$. It can be seen that all knee structures, especially the $A C L$ and IM, may be at a high risk of injury during the long jump. While the distal segment

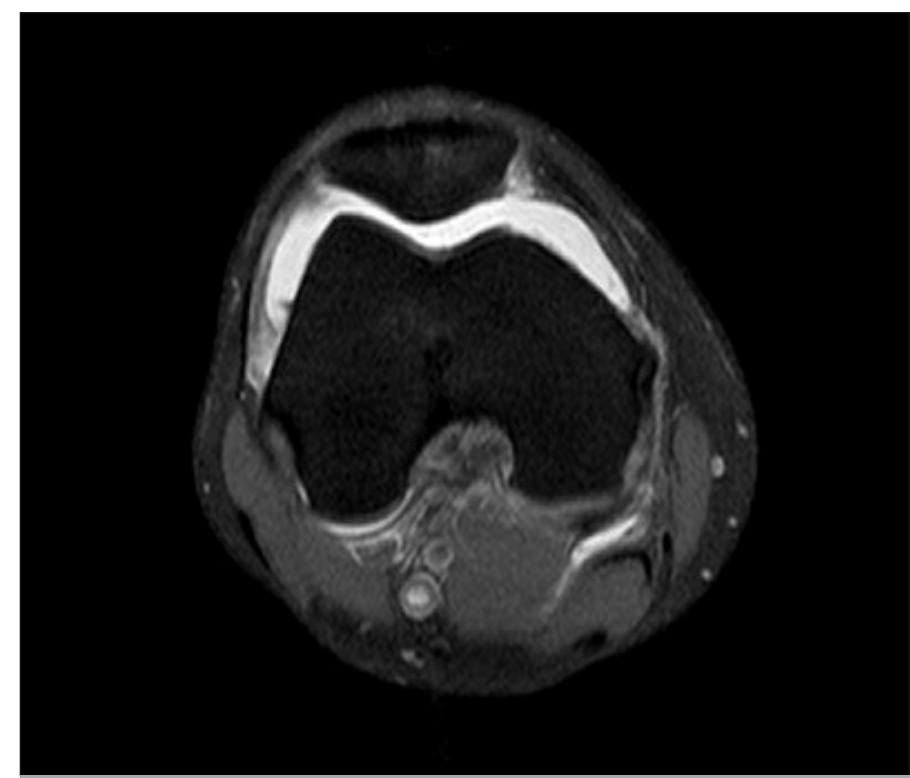

Figure 3. Axial MRI section showing intra-articular effusion

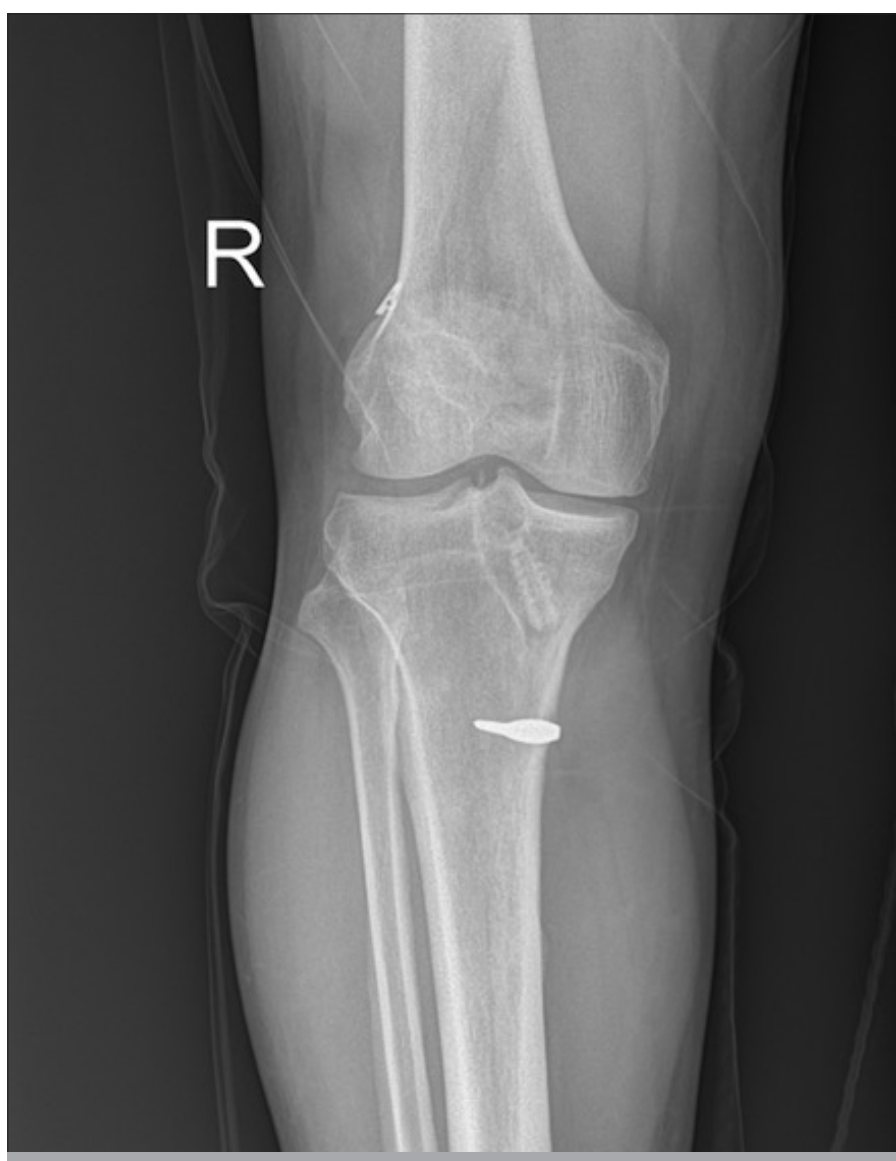

Figure 4. Anterior-posterior radiograph of the knee after the $A C L$ reconstruction

Table 4. Evaluation of cases by the injured side

\begin{tabular}{|c|c|c|c|c|}
\hline & & \multicolumn{2}{|c|}{ Side } & \multirow[b]{3}{*}{${ }^{a} p$} \\
\hline & & \multirow{2}{*}{$\begin{array}{c}\text { Right }(n=43) \\
\text { Mean } \pm S D\end{array}$} & \multirow{2}{*}{$\begin{array}{c}\text { Left }(n=25) \\
\text { Mean } \pm \text { SD }\end{array}$} & \\
\hline & & & & \\
\hline \multirow[t]{2}{*}{ Number of Injuries; median (IQR) } & & $3.0(2.0-4.0)$ & $2.0(2.0-3 . .5)$ & ${ }^{\circ} 0.085$ \\
\hline & & n (\%) & $n(\%)$ & \\
\hline Bone marrow edema & & $32(74.4)$ & $14(56.0)$ & 0.117 \\
\hline Effusion & & $39(90.7)$ & $21(84.0)$ & d0.453 \\
\hline \multirow[t]{2}{*}{ Meniscal tear } & EM & $8(18.6)$ & $7(28.0)$ & 0.368 \\
\hline & IM & $28(65.1)$ & $15(50.0)$ & 0.673 \\
\hline \multirow[t]{4}{*}{ Ligament injury } & $A C L$ & $33(76.7)$ & $12(48.0)$ & $0.016^{\star}$ \\
\hline & LCL & $3(7.0)$ & $5(20.0)$ & ${ }^{\mathrm{d}} 0.133$ \\
\hline & $\mathrm{MCL}$ & 15 (34.9) & $2(8.0)$ & $0.014^{\star}$ \\
\hline & $\mathrm{PCL}$ & $1(2.3)$ & $2(8.0)$ & ${ }^{\mathrm{d}} 0.550$ \\
\hline \multirow[t]{3}{*}{ Injury classification } & 1 & $5(11.6)$ & $5(20.0)$ & ${ }^{\mathrm{d}} 0.480$ \\
\hline & 2 & $18(41.9)$ & $12(48.0)$ & 0.623 \\
\hline & 3 & $20(46.5)$ & $8(32.0)$ & 0.241 \\
\hline
\end{tabular}




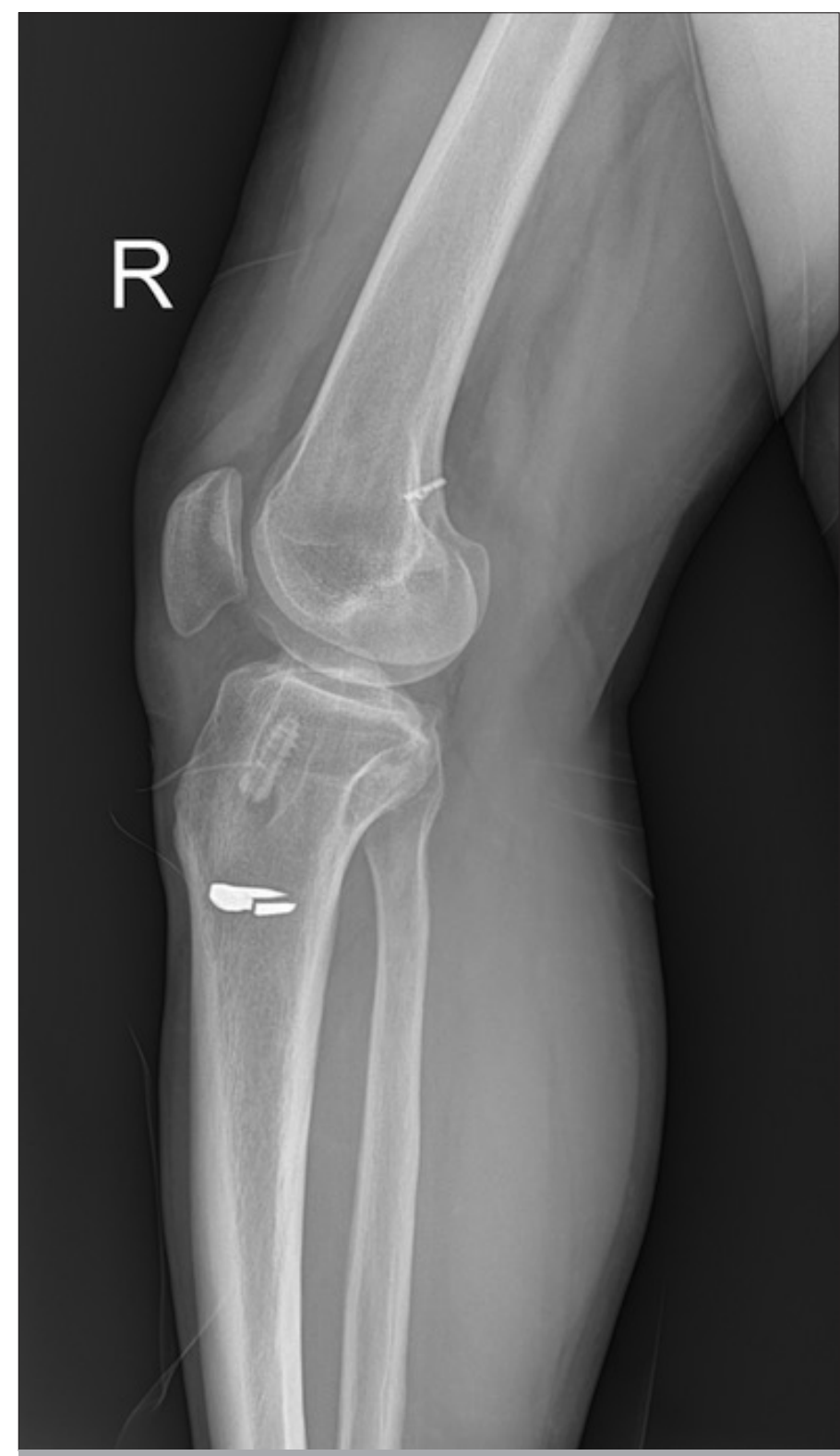

Figure 5. Knee lateral radiograph after the $\mathrm{ACL}$ reconstruction

Table 5. Investigation of the Relationship Between the Skip Distance and Injuries

\begin{tabular}{|l|c|c|}
\hline & & Number of Injuries \\
\hline Skip Distance & R & 0.216 \\
\hline & $P$ & 0.076 \\
\hline R: Spearman's correlation coefficient & & \\
\hline
\end{tabular}

is fixed during stroke on one foot forcing the knee to valgus and extension, a pivot injury or both mechanisms may lead to this condition (11, 12). Biomechanical and large-scale series studies are needed on this subject.

The ACL is the most frequently injured knee structure in sports practice (13). Jump, rotation, and deceleration during sportive activities may lead to an ACL injury (13). Majewski et al. (2) stated that the most common injury with $A C L$ was the medial meniscal tear. Injuries of $M C L, E M, P C L$, and $L C L$ were reported as other injuries with the $A C L$ rupture (14). PA et al. reported that $A C L$ injuries were most frequently associated with meniscal lesions (37\%). In our study, it was found that in patients with an ACL injury, 62.2\% had medial meniscus, $28.8 \%$ had a MCL, $20 \%$ had EM, $4.4 \%$ had $\mathrm{LCL}$, and $1.5 \%$ had PCL injury. It is noteworthy that the $A C L$ injury in the long jump is more likely to be seen with meniscus and other ligaments. Although not certain, it may be due to sudden and high-energy loading inside the joint in the long jump.

It is stated in the literature that the probability of injury of different knee structures may be high in different sports. For example, the highest probability of injury in football is indicated as the ACL (3). In 2015, in another research, it was found that in ice hockey, the most injured structure in the knee was MCL (14). Meniscal tears can be seen intensively in sports such as athletics and football (15). Likewise, in our study, it was found that the ACL and meniscal lesions were more frequent than other structures, and the probability of a combined injury was high.

Bone marrow edema is defined as an increase in the bone marrow signal during an MRI evaluation. It has been reported that this situation is due to a strong compressive loading and the possibility of appearing together with an ACL injury may be in the range of $80 \%$ and $84 \%(16,17)$. Although high pain levels are mentioned in patients with bone marrow edema, the effect on long-term functional results is unknown (18). In our study, an $\mathrm{ACL}$ injury was accompanied by bone marrow edema at $73.3 \%$, consistent with the literature.

In our study, we evaluated whether there was a relationship between the injured knee structures and the sprained side. Accordingly, there was no significant difference between the sprained side and bone marrow edema, effusion, meniscal lesion, LCL, and PCL injuries (Table 4). However, the incidence of ACL lesions in the right-sided injuries was found to be statistically significantly higher than in the left sided (effect size w, 0.293; post-hoc power, $0.676 ; p, 0.016 ; p<0.05)$. It was also found that the incidence of MCL lesions was significantly higher in the right-sided injuries than the left sided (effect size w, 0.299; post-hoc power, 0.694; $p$, $0.014 ; p<0.05)$. Although not definite, this may be related to the overload of the long jump on the right side during the descent phase and the central nervous system.

In the literature, no research has been found that evaluates injuries with the skip distance in the long jump. In our study, no significant relationship was found between the skip distance and the number and severity of the injuries around the knee $(p=0.76)$ (Table 5). Although not definite, these injuries may be due to errors in the jumping technique rather than the skip distance. The major limitations of our study were its retrospective nature and the fact that all of the cases detected by imaging methods could not be confirmed because surgery was not performed. Failure to evaluate professional long jumpers and inclusion of male gender only seem to be other shortcomings.

\section{CONCLUSION}

All knee structures including the ACL and medial meniscus during the long jump are highly at risk. High-energy combined injuries that are affecting more than one structure are also common. 
Ethics Committee Approval: Authors declared that the research was conducted according to the principles of the World Medical Association Declaration of Helsinki "Ethical Principles for Medical Research Involving Human Subjects", (amended in October 2013).

Informed Consent: Informed consent was not taken from patients due to the retrospective nature of the study.

Peer-review: Externally peer-reviewed.

Author Contributions: Concept - M.Ç.K., M.T.Ö.; Design - M.Ç.K., M.T.Ö.; Supervision - M.Ç.K., M.T.Ö.; Resources - M.Ç.K.; Materials M.Ç.K.; Data Collection and/or Processing - M.Ç.K.; Analysis and/or Interpretation - M.Ç.K., M.T.Ö.; Literature Search - M.Ç.K.; Writing Manuscript - M.Ç.K.; Critical Review - M.Ç.K., M.T.Ö.

Conflict of Interest: The authors have no conflict of interest to declare.

Financial Disclosure: The authors declared that this study has received no financial support.

\section{REFERENCES}

1. Nilstad A, Andersen TE, Bahr R, Holme I, Steffen K. Risk Factors for Lower Extremity Injuries in Elite Female Soccer Players. Am J Sports Med 2014; 42: 940-8. [CrossRef]

2. Majewski M, Susanne H, Klaus S. Epidemiology of athletic knee injuries: A 10-year study. Knee 2006; 13: 184-8. [CrossRef]

3. Hootman JM, Dick R, Agel J. Epidemiology of collegiate injuries for 15 sports: Summary and recommendations for injury prevention initiatives. J Athl Train 2007; 42: 311-9.

4. Etnoyer J, Cortes N, Ringleb SI, Van Lunen BL, Onate JA. Instruction and jump-landing kinematics in college-aged female athletes over time. J Athl Train 2013; 48: 161-71. [CrossRef]

5. Brumitt J, Heiderscheit BC, Manske RC, Niemuth PE, Rauh MJ. Lower extremity functional tests and risk of injury in division iii collegiate athletes. Int J Sport Phys Ther 2013; 8: 216-27.

6. Panteli FN, Theodorou A, Pilianidis T, Smirniotou A. Locomotor control in the long jump approach run in young novice athletes. J Sports Sci 2014; 32: 149-56. [CrossRef]

7. Surakka J, Aunola S, Nordblad T, Karppi SL, Alanen E. Feasibility of power-type strength training for middle aged men and women: Self perception, musculoskeletal symptoms, and injury rates. Br J Sports Med 2003; 37: 131-6. [CrossRef]

8. Cimino F, Volk BS, Setter D. Anterior cruciate ligament injury: Diagnosis, management, and prevention. Am Fam Physician 2010; 82: 917-22.

9. Steinbrück K. Epidemiology of sports injuries--25-year-analysis of sports orthopedic-traumatologic ambulatory care. Sportverletz Sportschaden 1999; 13: 38-52. [CrossRef]

10. Kuikka PI, Pihlajamaki HK, Mattila VM. Knee injuries related to sports in young adult males during military service - Incidence and risk factors. Scand J Med Sci Sport 2011; 23: 281-7. [CrossRef]

11. Alentorn-Geli E, Myer GD, Silvers HJ, Samitier G, Romero D, Lazaro-Haro $\mathrm{C}$, et al. Prevention of non-contact anterior cruciate ligament injuries in soccer players. Part 1: Mechanisms of injury and underlying risk factors. Knee Surg Sports Traumatol Arthrosc 2009; 17: 705-29. [CrossRef]

12. Shimokochi Y, Shultz SJ. Mechanisms of noncontact anterior cruciate ligament injury. J Athl Train 2008; 43: 396-408. [CrossRef]

13. LaBella CR, Hennrikus W, Hewett TE; Council on Sports Medicine and Fitness, and Section on Orthopaedics. Anterior cruciate ligament injuries: diagnosis, treatment, and prevention. Pediatrics 2014; 133: e1437-50. [CrossRef]

14. Nicolini AP, Carvalho RT, Matsuda MM, Sayum Filho J, Cohen M. Common injuries in athletes' knee: experience of a specialized center. Acta Ortop Bras 2014; 22: 127-31. [CrossRef]

15. Tuominen M, Stuart MJ, Aubry M, Kannus P, Parkkari J. Injuries in men's international ice hockey: A 7-year study of the International Ice Hockey Federation adult World Championship tournaments and Olympic Winter Games. Br J Sports Med 2015; 49: 30-6. [CrossRef]

16. Yoon $\mathrm{KH}, \mathrm{Yoo} \mathrm{JH}, \mathrm{Kim} \mathrm{K}-\mathrm{I}$. Bone contusion and associated meniscal and medial collateral ligament injury in patients with anterior cruciate ligament rupture. J Bone Joint Surg Am 2011; 93: 1510-8. [CrossRef]

17. Dunn WR, Spindler KP, Amendola A, Andrish JT, Kaeding CC, Marx RG, et al. Which preoperative factors, including bone bruise, are associated with knee pain/ symptoms at index anterior cruciate ligament reconstruction (ACLR)?: A multicenter orthopaedic outcomes network (MOON) aclr cohort study. Am J Sports Med 2010; 38: 1778-87. [CrossRef]

18. Papalia R, Torre G, Vasta S, Zampogna B, Pedersen DR, Denaro V, et al. Bone bruises in anterior cruciate ligament injured knee and longterm outcomes. A review of the evidence. Open access J Sport Med 2015; 6: 37-48. 